\title{
Preservasi Konten Lokal di Perpustakaan Perguruan Tinggi (Studi Kasus Medical Knowledge Center UPN Veteran Jakarta)
}

\author{
Dwi Fajar Saputra \\ dwifajar@upnvj.ac.id \\ Medical Knowledge Center, Fakultas Kedokteran, UPN Veteran Jakarta
}

\begin{abstract}
The college library is the center in the running of the wheel of disseminating knowledge. One of the collections found in the college library is local content. Local content has a variety of types, among others, student writings and lecturers' research results. Medical Knowledge Center as a center for depositing local content academicians of the Faculty of Medicine UPN Veteran Jakarta strives to facilitate the existing local content to be more optimally utilized. This research was conducted to determine the application of local content preservation in the Medical Knowledge Center in terms of processes and benefits. The method used is descriptive qualitative. Stages are carried out by identification, selection and decision making. Conclusion Local content becomes more organized, the value of existing knowledge is maintained and extends dissemination.
\end{abstract}

\begin{abstract}
Abstrak
Perpustakaan perguruan tinggi merupakan pusat dalam berjalannya roda penyebarluasan pengetahuan. Salah satu koleksi yang terdapat di Perpustakan perguruan tinggi adalah konten lokal. Konten lokal memiliki beragam jenis antara lain hasil karya tulis Mahasiswa dan hasil penelitian Dosen. Medical Knowledge Center sebagai pusat deposit konten lokal sivitas akademika Fakultas Kedokteran UPN Veteran Jakarta berusaha untuk memfasilitasi agar konten lokal yang ada menjadi lebih optimal pemanfaatannya. Penelitian ini dibuat untuk mengetahui penerapan preservasi konten lokal di Medical Knowledge Center dari segi proses dan manfaat. Metode yang digunakan dengan deskriptif kualitatif. Tahapan dilakukan dengan identifikasi, seleksi dan pengambilan keputusan. Kesimpulan konten lokal menjadi lebih tertata, nilai pengetahuan yang ada tetap terjaga dan memperluas diseminasi.
\end{abstract}

Kata kunci: $\quad$ Preservasi, Konten Lokal, Perpustakaan Perguruan Tinggi 


\section{Pendahuluan}

Medical knowledge center didirikan sejak 2014 dengan berlandaskan SKEP Dekan Fakultas Kedokteran UPN Veteran Jakarta. Namun koleksi konten lokal yang tersedia sudah ada dari tahun 1997 bersamaan dengan adanya skripsi hasil karya mahasiswa angkatan pertama. Dari tahun 1997 itu, proses deposit skripsi selalu dilakukan tetapi tidak tertata bahkan cenderung tidak diperhatikan sehingga nilai pengetahuan yang ada didalam skripsi tidak dapat dimanfaatkan dengan baik. Oleh karena itu, di tahun 2018 direncanakan untuk melakukan optimalisasi konten lokal dengan cara melakukan preservasi.

\section{Metode Penelitian}

Penelitian ini menggunakan penelitian kualitatif Metode deskriptif adalah metode penelitian yang memberikan gambaran atau uraian atas suatu keadaan sejelas mungkin tanpa ada perlakuan terhadap objek yang diteliti. ${ }^{1}$

Bogdan dan Biklen memberikan penjelasan tentang karakteristik dari penelitian kualitatif yaitu: (1) penelitian kualitatif dilakukan pada latar alamiah sebagai sumber langsung dan peneliti merupakan instrumen kunci; (2) bersifat deskriptif, yaitu menggambarkan situasi tertentu atau data yang dikumpulkan dalam bentuk kata-kata atau gambar-gambar daripada angkaangka; (3) lebih memperhatikan proses daripada hasil atau produk semata; (4) dalam menganalisis data cenderung secara induktif; dan (5) makna merupakan hal yang esensial bagi penelitian kualitatif. ${ }^{2}$

\section{Tinjauan Pustaka}

\section{Konten Lokal}

Konten lokal (Local content) adalah segala sesuatu yang bermuatan sumber pengetahuan/informasi yang asli dihasilkan oleh suatu institusi/

\footnotetext{
${ }^{1}$ Roni Kuntoro, Metode Penelitian, (Jakarta: PPM, 2005), hal. 105.

${ }^{2}$ Dalam Muhammad Adil, Tradisi Garang Model Transmisi, (Yogyakarta: Idea Press Yogyakarta, 2015), hal. 13.
} 
lembaga, perusahaan atau daerah sampai dengan negara, yang dapat dijadikan sumber pembelajaran (learning resources) dalam bentuk karya cetak maupun karya rekam.

Potensi local content dapat berupa :

1. Potensi suatu daerah/negara salah satunya kebudayaan, sejarah,pariwisata, perekonomian dan sebagainya, yang menjadi ciri khas dari suatu daerah/ negara.

2. Potensi local content perusahaan salah satunya sejarah perusahaan, perkembangan produk yang dihasilkan, dokumentasi suatu media.

3. Potensi local content institusi pendidikan atau perguruan tinggi yang terdiri para akademisi, reseachter, tenaga non educatif sebagai pengguna informasi pengetahuan aktif yang menghasilkan riset penelitian, Skripsi, Tugas Akhir, Laporan Akhir, artikel ilmiah, materi kuliah, kumpulan kebijakan pimpinan perguruan tinggi, sejarah perguruan tinggi atau event-event yang dilaksanakan oleh institusi/perguruan tinggi yang didokumentasikan baik tercetak maupun terekam.

4. Potensi local content lainnya yang dihasilkan oleh para professional Menghimpun, mengolah, menyimpan dan mendayagunakan serta melestarikan hasil karya cetak dan karya rekam ini sesuai dengan isi UU No.4 Tahun 1990 tentang Karya Cetak dan Karya Rekam yang pelaksanaannya diatur dalam PP 17 No.70 Tahun 1991, yang merupakan tugas dari pusat deposit, yaitu Perpustakaan Nasional atau Badan Perpustakaan Daerah ${ }^{3}$.

\section{Jenis-Jenis Konten Lokal}

Menurut ezema ${ }^{4}$, material konten lokal terdiri dari :

${ }^{3}$ M.A.F.J. Maronie, "Pengembangan koleksi local content di Badan Perpustakaan dan Arsip Daerah Provinsi Sulewesi Selatan” Repositori Institusi UIN Alauddin Makassar hal. 16, diakses dari http://repositori.uin-alauddin.ac.id/509 pada 12 November 2018

${ }^{4}$ Ifeanyi J. Ezema, (2013),"Local contents and the development of open access institutional repositories in Nigeria University libraries", Library Hi Tech, Vol. 31 Iss 2 pp. 323 - 340 Permanent link to this document:

http://dx.doi.org/10.1108/07378831311329086 


\begin{tabular}{|l|}
\hline Theses and dissertations \\
\hline Publications of staff \\
\hline Faculty/Departmental journals \\
\hline Conference proceedings \\
\hline Inaugural lectures \\
\hline Conference/seminar papers \\
\hline Institutional newsletters \\
\hline Senate publications \\
\hline Public lectures \\
\hline Vice Chancellor's addresses \\
\hline Faculty/Departmental reports \\
\hline Ceremonial reports \\
\hline Students' news magazines \\
\hline Course contents \\
\hline Local newspapers \\
\hline Lecture notes \\
\hline Students' term papers \\
\hline Examination question papers \\
\hline Students' industrial attachment reports \\
\hline
\end{tabular}

\section{Proses Preservasi Koleksi}

Tahap awal dalam proses preservasi konten lokal adalah melakukan identifikasi. Menurut Mardiastuti ${ }^{5}$, identifikasi koleksi dilakukan setidaknya dengan mempertimbangkan salah satu dari beberapa metode di bawah ini:

1. Kondisi dan penggunaan koleksi; identifikasi koleksi yang mengalami kerusakan dilakukan pada saat pengembalian pada sirkulasi, atau berdasarkan laporan dari pengguna kepada petugas.

${ }^{5}$ A. Mardiastuti, "Seleksi Dalam Kegiatan Preservasi Koleksi Perpustakaan" Naskah dari Researchgate hal. 3, diakses dari https://www.researchgate.net/publication/279174893_SELEKSI_ DALAM_KEGIATAN_PRESERVASI_KOLEKSI_PERPUSTAKAAN/download pada 12 November 2018. 
2. Kondisi dan proses pengolahan; koleksi yang memerlukan perhatian diidentifikasi pada saat kegiatan pengadaan (akuisisi), katalogisasi, dan kegiatan pemrosesan selanjutnya.

3. Kondisi koleksi pada jajaran koleksi; kegiatan yang khusus dilaksanakan dengan melakukan pemeriksaan langsung kondisi koleksi pada jajaran.

4. Koleksi dan pertimbangan kondisi; kegiatan review setiap koleksi dengan melibatkan seluruh petugas perpustakaan untuk menentukan koleksi yang penting dan memerlukan perhatian khusus, tanpa harus melihat langsung koleksi tersebut.

5. Review ilmiah; fakultas, para peneliti, dan para ahli dapat melakukan identifikasi koleksi apa saja yang mempunyai nilai ilmiah tinggi dan harus dilakukan preservasi.

6. Koleksi yang mudah mengalami kerusakan; koleksi dengan kondisi kerusakan karena seringnya penggunaan atau karena seringnya dipajang, perlu lebih diperhatikan dalam identifikasi kegiatan preservasi. Sebagai contoh: majalah, koran, dan jurnal

7. Koleksi yang mempunyai nilai khusus atau keunikan; koleksi yang bernilai istimewa, unik atau khusus perlu dipertimbangkan dalam identifikasi.

Tahap kedua adalah dengan melakukan seleksi. Menurut Harris dalam Mardiastuti mengemukakan tiga asumsi yang dapat dijadikan sebagai alasan mengapa seleksi pada preservasi bahan pustaka perlu dilakukan, sebagai berikut:

1. Bahwa tidak ada satu pun institusi perpustakaan yang mampu melaksanakan preservasi pada seluruh koleksi yang dimilikinya. Kerjasama dalam pelaksanaan preservasi mungkin akan dapat dilaksanakan, namun tidak akan cukup tersedia sumber daya untuk melaksanakan preservasi pada seluruh koleksi.

2. Bahwa untuk dapat melaksanakan preservasi koleksi, maka perlu disusun prioritas yang didasarkan pada tingkat kualitas koleksi dan tingkat kerapuhannya, sehingga preservasi akan dapat dilaksanakan seefisien mungkin. 
3. Tidak semua koleksi perlu dilakukan preservasi, dengan pertimbangan relevansinya di masa depan, atau sering tidaknya koleksi tersebut digunakan. ${ }^{6}$

Tahap Ketiga yaitu pengambilan keputusan, kriteria pengambilan keputusan antara lain :

1. Apakah koleksi tersebut mempunyai nilai artifaktual, yang meliputi koleksi yang berisi visualisasi, ilustrasi, gambar-gambar, lukisan, naskahnaskah dan arsip-arsip kuno, sangat penting untuk dilakukan preservasi

2. Apakah koleksi tersebut mempunyai kedudukan yang penting dalam suatu bidang studi atau kajian. Dalam hal ini perlu ditentukan isi yang terdapat dalam koleksi tersebut apakah berkedudukan sebagai sumber primer atau sekunder, dan apakah koleksi tersebut berada dalam daftar penting dari bibliografi, indeks atau abstrak bidang kajian tersebut

3. Apakah koleksi dalam keadaan utuh, misalnya, terdapat halaman yang hilang, volume tidak lengkap. Jika terdapat kopi lain yang lebih lengkap maka koleksi yang lengkap tersebut adalah yang dipreservasi. Jika koleksi tersebut merupakan satu-satunya yang dimiliki maka perlu dilengkapi terlebih dahulu, dengan jalan meminjam dari perpustakaan lain untuk difotokopi bagian yang hilang tersebut

4. Apakah preservasi akan disimpan dalam format mikro dengan tidak terlalu membatasi akses. Jurnal ilmiah dapat dialihkan dalam bentuk mikrofilm karena jika tetap disimpan dalam bentuk aslinya akan memakan banyak tempat

5. Apakah koleksi akan sering dipergunakan untuk saat ini dan waktu yang akan datang. Apabila koleksi tersebut sering digunakan maka penting untuk dilakukan preservasi, dibandingkan dengan koleksi yang jarang digunakan

6. Apakah ada pembatasan yang terkait dengan undang-undang hak cipta.

7. Apakah koleksi tersebut mudah rusak atau hilang

${ }^{6}$ Harris, Carolyn. Selection for preservation in "Preservation of information: issues and planning" edited by Paul N. Banks and Roberta Pillete. Chicago : American Library Association, 2000. pp 206-264 
8. Apakah koleksi tersebut mempunyai nilai penelitian permanen. ${ }^{7}$

\section{Pembahasan}

\section{Identifikasi}

Proses yang dilakukan dalam melakukan identifikasi

1. Mengumpulkan semua konten lokal dalam ruangan khusus.

2. Menentukan jenis konten lokal. Terdiri dari skripsi, prosiding, karya tulis hasil penerimaan hibah, artikel dosen terpublikasi di jurnal nasional dan internasional dan karya tulis mahasiswa.

3. Mengelompokan sifat konten lokal yang born digital dan masih cetak. Hasil yang didapatkan

Tabel 1

\begin{tabular}{|c|c|c|}
\hline Jenis & Total Seharusnya & Terindentifikasi \\
\hline Skripsi & 1920 item & 1802 item \\
\hline Prosiding & - & 36 item \\
\hline Karya Tulis Hasil Penerimaan Hibah & - & 54 item \\
\hline Artikel Dosen Publikasi Jurnal Nasional & - & 127 item \\
\hline $\begin{array}{l}\text { Artikel Dosen Publikasi Jurnal Interna- } \\
\text { sional }\end{array}$ & - & 4 item \\
\hline Total & 1920 item & 2023 item \\
\hline
\end{tabular}

Tabel 2

\begin{tabular}{lc}
\hline \multicolumn{1}{c}{ Sifat } & Total Satuan \\
\hline Born digital & 1181 item \\
\hline Cetak & 842 item \\
\hline \multicolumn{1}{c}{ Total } & $\mathbf{2 0 2 3}$ item \\
\hline
\end{tabular}

${ }^{7}$ A. Mardiastuti, "Seleksi Dalam Kegiatan Preservasi Koleksi Perpustakaan” Naskah dari Researchgate hal. 3, diakses dari https://www.researchgate.net/publication/279174893_SELEKSI_ DALAM_KEGIATAN_PRESERVASI_KOLEKSI_PERPUSTAKAAN/download pada 12 November 2018. 
Pada tabel 1, total seharusnya didapatkan dari data di satker pendidikan dan pengajaran bahwa terdapat 1920 skripsi yang sudah dihasilkan oleh mahasiswa Fakultas Kedokteran UPN Veteran Jakarta sejak tahun 1997 sampai tahun 2017. Namun yang hanya ada 1802 skripsi tersimpan di Medical Knowledge Center. Sedangkan di tabel 2, versi cetak total 842 berasal dari skripsi. Karna baru ada pada tahun 2012 diwajibkan peraturan memberikan versi elektronik skripsi dalam bentuk CD.

\section{Seleksi}

Proses seleksi dilakukan dengan cara

1. Menentukan konten lokal yang harus segera di preservasi berdasarkan masih bersifat cetak dan nilai pengetahuan.

2. Bagi konten lokal yang masih bersifat cetak, diseleksi dengan melihat dari beberapa kategori yaitu masih utuh seluruh halaman, tidak terkena jamur dan tidak terkena serangan hewan.

Tabel 3

\begin{tabular}{lcc}
\hline \multicolumn{1}{c}{ Jenis } & Terindentifikasi & Terseleksi \\
\hline Skripsi & 1802 item & 1663 item \\
\hline Prosiding & 36 item & 36 item \\
\hline Karya Tulis Hasil Penerimaan Hibah & 54 item & 54 item \\
\hline Artikel Dosen Publikasi Jurnal Nasional & 127 item & 127 item \\
\hline Artikel Dosen Publikasi Jurnal Internasional & 4 item & 4 item \\
\hline \multicolumn{1}{c}{ Total } & $\mathbf{2 0 2 3}$ item & $\mathbf{1 8 8 4}$ item \\
\hline
\end{tabular}

Pada tabel 3, ditemukan 139 skripsi yang terkena serangan hewan dan tidak layak untuk dipreservasi.

\section{Pengambilan Keputusan}

Proses pengambilan keputusan berdasarkan dari kepentingan akademik dan kebutuhan jenjang jabatan Dosen. Bagi konten lokal yang berkaitan dengan hal tersebut akan disimpan didalam sistem repositori 
institusi guna mengikuti kebijakan pemerintah. Lalu untuk yang lain akan disimpan terlebih dahulu kedalam format pdf di CD ROM dan server.

\section{Teknis Pelaksanaan Preservasi Versi Cetak (Skripsi)}

Pra Preservasi $\longrightarrow$ Proses Preservasi $\longrightarrow$ Pasca Preservasi

a. Pra Preservasi

Sebelum kegiatan preservasi dimulai, ada beberapa hal yang harus dilakukan yaitu:

1) Skripsi yang akan dikonversi dari cetak menjadi digital perlu diseleksi untuk mendapatkan hasil yang sesuai dengan tujuan alih media.

2) Pembongkaran jilid skripsi agar bisa dibaca alat pemindai (scanner). Proses ini perlu dilakukan untuk memudahkan operator pemindai dalam hal ini staf pengelola perpustakaan melakukan proses pemindaian lembar demi lembar dari skripsi tersebut.

3) Selanjutnya, kita persiapkan terlebih dahulu perangkat keras dan perangkat lunak yang mendukung prosedur alih media bahan pustaka. Adapun perangkat keras dan perangkat lunak yang dibutuhkan seperti yang ditulis oleh Saleh antara lain:

- Perangkat keras meliputi: a. komputer dan b. alat pemindai (scanner).

- Perangkat lunak meliputi: a. Epsonscan atau perangkat lunak pemindai yang lain, b. Adobe photoshop (versi lengkap) untuk menghasilkan dokumen dalam bentuk PDF (Portable Document Format) ${ }^{9}$.

b. Proses Preservasi

Selanjutnya berdasarkan teori saleh ${ }^{10}$, proses preservasi sebagai berikut:

1) Pembacaan halaman demi halaman dokumen menggunakan alat

${ }^{8}$ Abdul Rahman Saleh, Membangun Perpustakaan Digital: Step by Step, (Jakarta: Sagung Seto, 2010), hal. 11.

${ }^{9}$ Abdul Rahman Saleh,..., hal. 11.

${ }^{10}$ Abdul Rahman Saleh,..., hal. 13. 
pemindai yang kemudian disimpan dalam bentuk PDF. Hasil dari proses ini adalah dookumen dalam bentuk elektronik atau file komputer.

2) Pengeditan hasil pemindaian walaupun sudah dalam bentuk elektronik, namun masih perlu diedit, terutama jika kertas yang ditemukan pada saat scanning tidak tepat benar. Oleh karena itu perlu dilakukan editing seperti pemotongan pinggiran halaman, pembalikan halaman, dan lain-lain sehingga hasilnya menjadi lebih mudah dan lebih enak dibaca. Selain itu perlu juga dilakukan penggabungan halaman jika pemindaian dilakukan secara sepotongsepotong.

3) Pembuatan serta pengolahan metadata (basis data) agar skripsi tersebut dapat diakses dengan cepat. Perangkat lunak yang dipakai Omeka.

4) Melengkapi basis data dengan abstrak. Hal ini sangat perlu untuk dilakukan, karena dokumen berisi informasi ilmiah.

5) Proses selanjutnya ialah pemindahan atau penulisan dokumen PDF serta basis data ke CD-R dan server. Setelah skripsi digital selesai, maka tahap berikutnya adalah mengumpulkan dokumen-dokumen tersebut, menata, serta menggandakan ke dalam CD-R dan server. Kemudian jika menggunakan CD-R atau DVD maka harus diberi label agar urutan publikasi dapat diketahui dengan jelas.

c. Pasca Preservasi

Proses terakhir adalah memperbaiki kembali koleksi yang sebelumnya dibongkar. Perbaikan ini dilakukan dengan melakukan penjilidan kembali skripsi yang sudah dibongkar. Jika skripsi tersebut masih diperlukan bentuk tercetaknya maka dapat dikembalikan ke bagian koleksi yang menyimpan bahan-bahan tercetak. Jika skripsi tersebut sudah melebihi 5 tahun masa terbit, maka akan dilakukan proses penyiangan koleksi. 


\section{Manfaat dari Preservasi Konten Lokal}

1. Memperpanjang nilai pengetahuan dari konten lokal.

Konten lokal yang mudah rusak akan serangan hewan, jamur dan kejadian yang tidak diduga menjadi lebih terjaga nilai pengetahuannya berkat preservasi sehingga dapat dimanfaatkan lebih lama oleh pemustaka.

2. Mempermudah proses temu kembali.

Proses temu kembali informasi bagi konten lokal menjadi lebih mudah karena hasil dari preservasi yang melibatkan perangkat keras dan lunak yang berbasis website.

3. Menghemat tempat.

Dengan adanya preservasi, penyimpanan konten lokal yang bersifat cetak menjadi lebih tertata karena hanya tersimpan 5 tahun terakhir di rak.

4. Mempermudah tata kelola arsip dinamis dan statis.

Tata kelola arsip dinamis dan statis berkaitan dengan konten lokal, yang awalnya memerlukan beberapa tahap administratif dan pencatatan secara manual oleh Pustakawan, dengan adanya preservasi menjadi lebih baik. Contoh untuk diinformasikan ke pemustaka, rekod metadatanya lebih lengkap.

\section{Penutup}

Preservasi dijalankan selama 4 bulan, dalam kurun waktu tersebut menghasilkan kumpulan file yang tersimpan didalam CD-R dan Server. Selanjutnya akan secara berkala dimasukkan kedalam sistem repositori intitusi. Secara umum konten lokal di Medical Knowledge Center dapat terbilang terlambat dalam dilakukan preservasi. Terdiri dari 139 item skripsi yang terkena serangan hewan, hal ini sangat disayangkan dan menjadi pelajaran untuk pengembangan kedepan. Saran dari kegitan ini, diperlukan suatu road map agar memiliki perencanaan yang jelas dan mendapatkan capaian sesuai dengan kebutuhan. 


\section{Daftar Pustaka}

Kuntoro, Roni. 2005. Metode Penelitian, Jakarta, PPM.

Adil, Muhammad. 2015. Tradisi Garang Model Transmisi, Yogyakarta, Idea Press.

Maronie, M.A.F.J. Pengembangan koleksi local content di Badan Perpustakaan dan Arsip Daerah Provinsi Sulewesi Selatan <http://repositori.uinalauddin.ac.id/509 Tanggal akses 12 November 2018>

Ezema, I.J. Local contents and the development of open access institutional repositories in Nigeria University libraries, <http://dx.doi. org/10.1108/07378831311329086 Tanggal akses 10 November 2018>

Mardiastuti, A. Seleksi Dalam Kegiatan Preservasi Koleksi Perpustakaan $<$ https://www.researchgate.net/publication/279174893_SELEKSI_ DALAM_KEGIATAN_PRESERVASI_KOLEKSI_PERPUSTAKAAN/ download Tanggal akses 12 November 2018>

Harris, Carolyn. Selection for preservation in "Preservation of information : issues and planning" edited by Paul N. Banks and Roberta Pillete. American Library Association, 2000.

Saleh, Abdul Rahman. 2010. Membangun Perpustakaan Digital: Step by Step, Jakarta, Sagung Seto. 